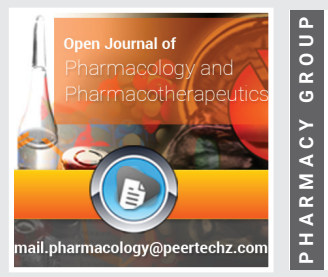

\section{Key points in effective inhaler technique training for asthma and COPD patients}

\author{
Hiroyuki Ohbayashi*
}

General Incorporated Association, Academy of Inhalation Methods, Representative Director, Tohno Chuo Clinic, 1-14-1 Matsugase-cho, Mizunami City, Gifu 509-6134, Japan
Received: 15 April, 2020

Accepted: 29 May, 2020

Published: 30 May, 2020

*Corresponding author: Hiroyuki Ohbayashi, MD, PhD, FCCP, General Incorporated Association, Academy of Inhalation Methods, Representative Director, Nagoya University, Tohno Chuo Clinic, 1-14-1 Matsugase-cho, Mizunami City, Gifu 509-6134, Japan, Tel: +81-572-671118; Fax: +81-572-67-2277;

E-mail: ohbayasi@nn.iij4u.or.jp

Keywords: Adherence; Inhalation device; Inhaler mishandling; Inhalation therapy

https://www. peertechz.com

Check for updates

\begin{abstract}
Inhalation therapy involves two types of adherence: adherence to the drug and adherence to the procedures for the inhalation device. Recent increases in the range of inhaled medications available have expanded treatment options, while simultaneously resulting in more complicated treatments for patients due to the increasing diversity of inhalation devices. Patients with asthma and chronic obstructive pulmonary disease (COPD) are required to not only take the agent at the indicated dosage, but also use the inhaler device in the proper manner with correct procedures. This review presents eight key points for training patients with asthma and COPD in effective inhaler technique. These points can help to ensure a good balance of adherence to both the medication and the inhalation device, and thereby maintain disease control in clinical settings.
\end{abstract}

\section{Main text}

Major therapeutic guidelines for asthma and chronic obstructive pulmonary disease (COPD), including the Global Initiative for Asthma (GINA) and Global Initiative for Chronic Obstructive Lung Disease (GOLD) guidelines, recommend inhalation medications as the first-line treatment for these obstructive pulmonary diseases [1,2]. However, patient adherence to inhaled drugs is generally poorer than adherence to oral medications $[3,4]$. Why is this? The answer lies in the method by which inhalation therapy is performed.

\section{Two types of adherence in inhalation therapy}

The difference between inhalation therapy and conventional oral medication lies not only in the administration route, but also in the existence of a special device (inhaler) for the secure storage and efficient delivery of the inhaled medication. Inhalation therapy therefore involves two types of adherence: adherence to the drug, as with standard oral drugs, and adherence to the procedures specific to the inhalation device. Both types of adherence are required for the optimal efficacy of inhalation therapy, and the foundations of treatment are weakened if either is neglected. To obtain the expected clinical effects, patients must not only take the agent at the indicated dosage, but also use the inhaler in the proper manner using the correct procedures. Although many different types of inhaler are available, pressurized metered dose inhalers (pMDIs) and dry powder inhalers (DPIs) are the devices most commonly used for drug delivery in the treatment of asthma and COPD. In recent years, types of inhalers have increased together with the range of inhaled medications. This has expanded treatment options, but at the same time resulted in more complicated treatments for patients with the increased diversity of inhalation devices. A large number of asthma and COPD patients use their inhaler devices incorrectly in daily clinical practice. Errors in device use are frequently found in both pMDIs [5] and DPIs [6]. Inhaler mishandling also continues to be common among experienced outpatients referred to chest clinics, in association with increased and unscheduled use of health-care resources [7]. Different devices exhibit different patterns of lung deposition, which may considerably affect the individual clinical effects $[8,9]$. Our recent study suggested that different devices for inhaled corticosteroid and long-acting beta agonist (ICS/LABA) combination therapy showed different clinical potency for lung functions [10]. Incorrect usage of inhaler devices may cause insufficient drug delivery and hence insufficient lung deposition, thereby leading to poor clinical control and worsened adherence of the patient with asthma and COPD. Inhaler misuse is also associated with increased 
risk of hospitalization, emergency room visits, and additional treatment with oral steroids and antimicrobials [11].

Therefore, even with an accurate diagnosis and drug selection, if the medication is ineffectively inhaled due to improper technique, symptoms will not improve sufficiently and adherence to the overall treatment may decline, jeopardizing the continuation of treatment. It is therefore essential that medical staff provide instructions not only for taking medications, but also for the inhalation technique to prevent improper operation of the inhaler and to maintain good adherence.

\section{Key points for effective inhaler technique training}

Medication adherence is maintained with detailed oral instructions, but inhalation devices require practical instruction using the actual inhaler to prevent incorrect operation. We keep the following eight points in mind to ensure effective instruction.

First, the cause of incorrect inhaler operation lies not only with the device itself, but in many cases with the patient. Some studies have reported that older age $[7,12]$ and female sex [12], are associated with higher device error rates. Incorrect operation is formed from a confluence of factors, including aging phenomena, physical handicaps, individual characteristics, personality, habits, and lifestyle. In cases of incorrect operation, one possibility is that the physician did not prescribe the device with attention to the appropriate matching of the patient and inhaler when the inhaler was first prescribed. With oral medications, prescriptions are made based on pharmacological information, such as the mechanisms of action of the drug and evidence for its efficacy. When physicians prescribe inhaled medications following the same flow as when prescribing oral medicines, the special inhaler for that inhaled drug is determined as a natural result, and in many cases the treatment follows that course unchanged in clinical settings. Omitting the important process of proper matching of the patient and device may set the stage for improper operation. Some inhalation drugs have an entire lineup, such as combination drugs, so when looking at the drugs for the intended use, we sometimes first match the patient and device before deciding the medication.

Second is to gather and retain patient background information by repeatedly observing, listening to, and talking with patients about things such as aging phenomena, physical handicaps, and individual characteristics, even during the process of fitting the patient and inhalation device when providing inhaler technique training. This is key to overcoming incorrect operation. An unexpectedly large number of patients cannot effectively inhale the medication despite performing the inhalation each day in the prescribed manner. This may sometimes be caused by unexpected variables, such as denture use. We have previously reported on the influence of dentures on residual inhaled corticosteroids in the mouths of elderly asthma patients [13]. Inhaler mishandling may increase the incorrect deposition of drugs in the mouth rather than the lungs.
This information is important to discovering and correcting causes of lapses into individual styles of mistaken operation. Providing inhaler technique guidance continually and repeatedly, and not just once in the beginning, is also essential [14]. This is because the reason for incorrect operation changes over time, due to circumstances such as aging phenomena in patients.

Third is that training in inhaler technique must not be taken as simply an explanation of the procedural instructions for the inhalation operation that have been prepared by the pharmaceutical company. Diagrams and photos in the instructions capture precise moments in the operation of the inhaler, but show only a single scene in the procedure and cannot go beyond the limitations of still images. The gaps between those discontinuous still images are filled in by the patients' own imaginations. This can give rise to self-interpretations and misunderstandings, in turn causing incorrect operation. Inhaler technique training should be provided with practical instruction in the dynamic, continuous flow of the operation procedure. The importance of still images of each scene can be understood and implemented by the patient only after they have comprehended the overall flow of operations.

Fourth, to provide effective training in inhaler technique, positioning with the patient during the inhalation instruction is important. Facing each other over the counter of a pharmacy or elsewhere may at first seem appropriate, but is undesirable for inhalation instruction. Facing patients directly is more likely to result in unnecessary nervousness, and if the person providing instruction uses the right hand for the operational technique and the patient performs the operation with their diagonally opposed right hand, and a reverse right-left perceptual illusion temporarily results. In some cases, patients will be unsure about left and right after returning home. Inhaler technique training should be provided while sitting next to the patient and communicating well.

Fifth, the hand used to operate and hold the device should be determined in consideration of the patient's dominant hand. Unnecessary or incorrect operation in the series of inhalation technique operations can be reliably decreased by not switching the hand that is used.

Sixth, when a new and novel medication enters the market and the inhalation device changes with the new medication, the prescription should not be changed without careful consideration and the inhaler to which the patient is accustomed should be retained whenever possible. If the medication is to be changed, a change between medications provided by the same inhaler is preferable, as changing inhalers could result in decreased adherence. There are also cases in which clinical effects differ with different inhalers even when the medication remains unchanged [15]. Furthermore, use of multiple inhalers often occurs in actual clinical practice. The higher error frequency reported with usage of multiple inhalers may be due to the higher burden and confusion associated with the use of different devices [16].

Seventh, the assumption by medical personnel that patients know to inhale inhalation medications should be abandoned. It 
is not necessarily true that an inhalation drug will be inhaled. In our experience, many patients blow instead of inhaling, along with cases in which patients have set up devices indoors on the assumption that they are the same as air fresheners. Other patients have thought the same mechanism is the same as an insecticide and have turned the inhaler upside-down to use an aerosol formulation. Medical professionals should not arbitrarily assume that something is obvious, and instruction should be given while keeping in mind that the things that are obvious to some people may not be obvious to others.

Eighth, inhaler technique training should be provided by the entire medical team, not a single doctor, pharmacist, or nurse. To overcome mistakes in operation, understanding, accumulating, and sharing patient information is important, such as findings regarding aging phenomena and handicaps. Information obtained by medical staff other than physicians who have more conversational time and opportunities with patients can often provide hints and opportunities for overcoming incorrect operation. Correct inhaler technique can influence inhaler use, patient satisfaction, and adherence [17], all of which are pivotal to achieving better management of asthma and COPD.

Adherence is an important factor that is directly linked to disease control in asthma and COPD [18] and the purpose of inhaler technique training is to maintain a good balance of adherence for both the medication and the delivery device. Based on the above eight points, favorable patient adherence and disease control should be able to be maintained by providing continuing inhaler technique training in clinical settings.

\section{References}

1. GINA main report. Global Strategy for asthma management and prevention, updated 2020. Link: https://bit.ly/3etJROn

2. Vogelmeier CF, Criner GJ, Martinez FJ, Anzueto A, Barnes PJ, et al. (2017) Global strategy for the diagnosis, management, and prevention of chronic obstructive pulmonary disease, updated 2017. Am J Respir Crit Care Med 195 557-582. Link: https://bit.ly/2AnWiMk

3. Breekveldt-Postma NS, Koerselman J, Erkens JA, Molen T Lammers JJ, et al. (2008) Treatment with inhaled corticosteroids in asthma is too often discontinued. Pharmacoepidemiol Drug Saf 17: 411-422. Link: https://bit.ly/2yH05SS

4. Cramer JA, Bradley-Kennedy C, Scalera A (2007) Treatment persistence and compliance with medications for chronic obstructive pulmonary disease. Can Respir J 14: 25-29. Link: https://bit.ly/3ezglGr

5. Horsley MG, Bailie GR (1988) Risk Factors for Inadequate Use of Pressurized Aerosol Inhalers. J Clin Pharm Ther 13: 139-143. Link: https://bit.ly/3dqiGnj
6. Lavorini F, Magnan A, Dubus JC, Voshaar T, Corbetta L, et al. (2008) Effect of Incorrect Use of Dry Powder Inhalers on Management of Patients With Asthma and COPD. Respir Med 102: 593-604. Link: https://bit.ly/36GsQNO

7. Melani AS, Bonavia M, Cilenti V, Cinti C, Lodi M, et al. (2011) Inhaler mishandling remains common in real life and is associated with reduced disease control. Respir Med 105: 930-938. Link: https://bit.ly/2zJh3IL

8. Ohbayashi H, Adachi M (2008) Hydrofluoroalkane-beclomethasone dipropionate effectively improves airway eosinophilic inflammation including the distal airways of patients with mild to moderate persistent asthma as compared with FP in a randomized open double-cross study. Allergology Int 53: 231-219. Link: https://bit.ly/3gxqs0v

9. Gustafsson P, Taylor A, Zanen P, Chrystyn H (2005)Can Patients Use All Dry Powder Inhalers Equally Well? Int J Clin Pract Suppl 13-18. Link: https://bit.ly/3cal9PX

10. Ohbayashi H, Kudo S, Ariga M (2018) Evaluation of Rapid Onset of Action of ICS/LABA Combination Therapy on Respiratory Function in Asthma Patients: A Single-Center, Open-Label, Randomized, Cross-Over Trial. Pulmonary Therapy 4: 159-169. Link: https://bit.ly/2AoD9tJ

11. Melani AS, Bonavia M, Cilenti V, Aliani M, Neri M, et al. (2011) Inhaler Mishandling Remains Common in Real Life and Is Associated With Reduced Disease Control. Respir Med 105: 930-938. Link: https://bit.ly/3ezi9zd

12. Chorao P, Pereira AM, Fonseca JA (2014) Inhaler devices in asthma and COPD-An assessment of inhaler technique and patient preferences. Respir Med 108: 968-975. Link: https://bit.ly/2BdM81u

13. Ohbayashi $H$, Adachi $M$ (2012) Influence of dentures on residual inhaled corticosteroids in the mouths of elderly asthma patients. Resp Invest 5: 54-61. Link: https://bit.ly/2ZOGL3a

14. Takaku Y, Kurashima K, Ohta C, Ishiguro T, Kagiyama N, et al. (2017) How Many Instructions Are Required to Correct Inhalation Errors in Patients With Asthma and Chronic Obstructive Pulmonary Disease? Respir Med 123: 110 115. Link: https://bit.ly/2TPqAyO

15. Jones R, Martin J, Thomas V, Skinner D, Marshall J, et al. (2017) The Comparative Effectiveness of Initiating Fluticasone/Salmeterol Combination Therapy via pMDI Versus DPI in Reducing Exacerbations and Treatment Escalation in COPD: A UK Database Study. Int J Chron Obstruct Pulmon Dis 12: 2445-2454. Link: https://bit.ly/2XbCh4D

16. Rootmensen GN, Van Keimpema ARJ, Jansen HM, de Haan RJ (2010) Predictors of incorrect inhalation technique in patients with asthma or COPD: A study using a validated videotaped scoring method. J Aerosol Med Pulm Drug Deliv 23: 323-328. Link: https://bit.ly/2TNeGoM

17. Ohbayashi H, Kudo S, Ishikawa T (2017) Inhaler Operability and Patient Satisfaction Regarding Genuair and Respimat ${ }^{\circledR}$ Inhalers for Chronic Obstructive Pulmonary Disease: A Randomized Crossover Study. Pulmonary Therapy 3: 173-185. Link: https://bit.ly/2B7Eo0Q

18. Giraud V, Roche N (2002) Misuse of corticosteroid metered-dose inhaler is associated with decreased asthma stability. Eur Respir J. 19: 246-251. Link: https://bit.ly/2XcFdOv

Copyright: @ 2020 Ohbayashi $\mathrm{H}$. This is an open-access article distributed under the terms of the Creative Commons Attribution License, which permits unrestricted use, distribution, and r eproduction in any medium, provided the original author and source are credited. 